\title{
ASBESTOS-FREE AUTOCLAVED WOOD FIBER-CEMENT SHEETS FROM RECYCLED OLD CORRUGATED CONTAINERS AND KRAFT PULP OF DOUGLAS FIR: PROPERTIES AND SCANNING ELECTRON MICROSCOPY
}

\author{
Divino Eterno Teixeira ${ }^{1, \star}$
}

\begin{abstract}
This study was conducted in cooperation with a United States pulp and paper company targeting part of the pulp production as raw material for fiber-reinforced cement sheets manufacturing. Virgin kraft pulp of Douglas fir (Pseudotsuga menziesii) and recycled fiber of old corrugated containers were used in making wood fiber-cement flat sheets. The physical and mechanical properties of the sheets were compared with an available commercial product. Results showed that Douglas fir fiber is a potential choice as reinforcement for wood fiber-cement sheets, as this fiber type outperformed the commercial ones for most of the properties studied. The difference in kappa number from 25 to 35 did not have any effect on the properties of Douglas fir sheets. Even recycled old corrugated containers fiber provided sheets with some properties comparable to the commercial product. Scanning electron microscopy analysis showed that a dual mechanism of fiber breakage and pull out occurred at rupture.
\end{abstract}

Keywords: Fiber refining, kappa number, mechanical properties, physical properties, Pseudotsuga menziesii.

\section{INTRODUCTION}

Inorganic-bonded wood particle and fiber composites constitute a growing industry in North America. In particular, manufacturers of fiber-reinforced cement (FRC) sheets were forced to shift from using asbestos to using other sources of fiber due to health concerns. Synthetic (PVA, glass, steel, carbon, kevlar, polypropylene) as well as natural fibers have been used as possible sources for nonasbestos FRC products (Marques et al. 2016, Soydan et al. 2018, Frazão et al. 2018). Cellulose fibers have emerged as the major replacement material for reinforcing fiber cement composites due to their competitive cost, acceptable fiber properties, and relative energy-efficiency (Cheng et al. 2018).

Research and industry of wood fiber-cement (WFC) sheets uses mainly Eucalyptus and Pinus (primarily Pinus radiata) pulps in the Hatschek process (Santos et al. 2015, Fonseca et al. 2016). Replacement of kraft fibers with inexpensive recycled fibers might also help make the fiber-cement products more cost effective. Some studies (Alda and Torrea 2006, Teixeira 2012, Khoramia et al. 2016, Sahin et al. 2017) have also evaluated the feasibility of using recycled fibers such as old newspaper (ONP) and old corrugated containers (OCC) as raw material for WFC composites. Results obtained add to the database of possible alternative fiber sources in case of shortage of radiata pine fiber or high pressure on the price.

According to the American Forest \& Paper Association (AF\&PA 2018a), the recovery rate of OCC/Unbleached Kraft papers in the U.S. was $88,8 \%$ in 2017, a net total of 29134 tons. As for the recovery of Old Newspapers/Mechanical Papers, the rate in 2017 amounted 76,8\% or 5,6 million tons

\footnotetext{
${ }^{1}$ Forest Products Laboratory (LPF), Brazilian Forest Service (SFB), Brasília-DF, Brazil.

•Corresponding author: divino.teixeira@florestal.gov.br

Received: 03.06. 2016 Accepted: 18.07.2018
} 
(AF\&PA 2018b). The possibility of fiber fractionating and refining of these kinds of fibers adds a great amount of raw material to the WFC industry (Teixeira 2012).

With some 1100 production flat sheet plants worldwide, demanding approximately a half million tons of fibers as reinforcement, global expansion of fiber-cement products demand to 2019 is projected at 4,4\%/year to 32,6 million metric tons in its various applications (The Freedonia Group 2018). For example, fiber cement's features such as ability to mimic the appearance of wood, aesthetics, greater durability, will boost demand in siding and roofing applications.

Although use of asbestos fiber must continue for some time in some countries due to economic and political factors, there is a gap that will eventually need to be filled in developing countries when asbestos is replaced. Inorganic bonded fiber composites studies include alternative fiber sources such as OCC, bagasse, coir, bamboo, groundwood, wheat straw, babaçu fibers, plastic, sisal pulp, coconut (Cocos nucifera L.) and brown pulp (Almeida et al. 2002, Abdel-Kader and Darweesh 2010, Araújo et al. 2011, Ferraz et al. 2011, Teixeira 2012, Marques et al. 2016, Farrapo et al. 2017).

Fiber from various natural sources such as eucalyptus, pine, araucaria, has been tested (Fonseca et al. 2016, Soydan et al. 2018). Up to the present, the highest strength in composite materials was achieved with sheets autoclaved using brown kraft pulp (Moslemi 2008). One problem faced by researchers was the poor ability of wood fibers to trap cement particles during the sheet manufacturing process, which can be overcome with the addition of supplementary cementitious materials (Wei et al. 2016). A major collaborative study between a giant fiber-cement company and the CSIRO institute from Australia was successful in overcoming this problem. Refinement of fibers caused the fibrils to be exposed and to increase the contact areas of the fiber and the cement. However, little literature was disclosed to the public since much of the research was carried out by fiber-cement manufacturing companies and was kept for their private use.

With regard to the curing of WFC sheets, the autoclave process, as opposed to air curing, has been favored in Australia and in the United States. Autoclave curing does not favor fibers with higher kappa numbers (high lignin content) because it promotes the release of excess sugar not eliminated in the cooking process. This free sugar interferes with cement setting.

Fibers derived from cellulose pulp are used as reinforcing material to combat cement cracking in WFC composites. They increase the toughness and cracking resistance of the composite (Moslemi 2008, Ardanuy et al. 2015, Cheng et al. 2018). Variables such as fiber length, freeness, kappa number, fiber-to-mass ratio, fiber substitution level, and level of fiber refinement are important parameters in determining WFC properties (Moslemi 2008, Teixeira 2012). The pulp kappa number is a measure of lignin content remaining in the stock after wood cooking. The higher the kappa number, the higher the amount of lignin available in the furnish. It also gives an estimate of chemicals used in the bleaching process, since the need of lower kappa number relates to more chemicals usage. Lignin content influences cement setting (TAPPI 1994). Chemical pulps are preferable because most of the lignin is removed during the cooking process. Higher lignin content, as found in thermomechanical pulp, is not particularly good in autoclave curing.

In this study it was evaluated the physical and mechanical properties of experimental autoclaved WFC sheets made with kraft pulp from Douglas fir (Pseudotsuga menziessi) and from recycled fiber from old corrugated containers (OCC) as compared with an available commercial product. Additionally, scanning electron microscopy (SEM) analysis was conducted to analyze the fibers failure on the fractured surface.

\section{MATERIALS AND METHODS}

\section{Material}

Three experimental (Sheets A, B and C) and one commercial (Sheet D) WFC sheet types were evaluated in this study. Their physical and mechanical properties were characterized in an experimental program. The wood fiber-cement sheets used are described in Table 1. 
Table 1. WFC composition and treatments.

\begin{tabular}{|c|l|}
\hline Sheet Type & \multicolumn{1}{c|}{ Composition of the Sheets } \\
\hline A & $\begin{array}{l}\text { Douglas fir kraft fiber at kappa\# 25; thickness of 0,37 in.; SG of 1,2; } \\
\text { fiber refined (at 400 CSF) }\end{array}$ \\
\hline B & $\begin{array}{l}\text { Douglas fir kraft fiber at kappa\# 35; thickness of 0,37 in.; SG of 1,2; } \\
\text { fiber refined (at 400 CSF) }\end{array}$ \\
\hline C & $\begin{array}{l}\text { Recycled OCC fiber at kappa\# 75; thickness of 0,37 in.; SG of 1,2; } \\
\text { fiber unrefined (at 580 CSF) }\end{array}$ \\
\hline D & $\begin{array}{l}\text { Commercial product; thickness of } 0,32 \text { in.; SG of 1,33; } \\
\text { fiber refined (at 400 CSF) }\end{array}$ \\
\hline
\end{tabular}

All three experimental WFC product types (A, B and C) were manufactured by the slurry-vacuum dewatered technique described in detail by Teixeira (2012). Curing in an autoclave completed the process. They were manufactured to a binder ratio of $0,1 / 0,7 / 1,0$ (clay/cement/silica) by mass and fiber-to-mass ratio (FMR) of 10 percent based on solid contents in a single layer forming process. The method used here aimed to reproduce an industrial manufacturing process. Eight sheets, measuring each 12 by 10 inches ( 305 by $254 \mathrm{~mm}$ ), were manufactured per product type.

The exact composition of the commercial product (D) and its manufacturing details were not available from the manufacturer, whose name is not disclosed for the sake of privacy.

\section{Sheets Testing}

One sample measuring $9 \frac{1}{2}$ by 2 inches $(241$ by $50 \mathrm{~mm}$ ) was cut from each sheet and allowed to reach equilibrium at $77^{\circ} \mathrm{F}\left(25^{\circ} \mathrm{C}\right)$ and $45 \%$ relative humidity. Tests were conducted according to ASTM C-1185-08 (ASTM-2008), except for stress at proportional limit, which was tested in accordance with ASTM D-1037-06 (ASTM-2006). The complete list of tests conducted and number of specimens per test is shown in Table 2.

Table 2. Outline of the WFC testing.

\begin{tabular}{|l|c|c|}
\hline \multirow{2}{*}{ Tests } & \multicolumn{2}{|c|}{ Number of samples } \\
\cline { 2 - 3 } & Per sheet & Total \\
\hline Mechanical & 1 & 8 \\
\hline Modulus of Rupture (R) & 1 & 8 \\
Modulus of Elasticity (E) & 1 & 8 \\
Breaking Moment (M) & 1 & 8 \\
Handleability Index (U) & 1 & 8 \\
Stress at Proportional Limit (S) & & \\
\hline Physical & 3 & 24 \\
\hline Thickness Swelling (TS) & 3 & 24 \\
Water Absorption (WABS) & 3 & 24 \\
Moisture Content (MC) & 3 & 24 \\
Specific Gravity (SG) & & \\
\hline
\end{tabular}

Specimens were tested for 3-point bending flexural strength using an Instron testing machine equipped with 1000-pound $(435 \mathrm{~kg})$ load cell at load speed of 0,20 in $(5 \mathrm{~mm}) / \mathrm{min}$.

Four specimens measuring $3 \frac{1}{2}$ by 2 inches ( 89 by $50 \mathrm{~mm}$ ) were cut from each specimen used for bending strength test and assigned to the physical tests. The specimens were then randomly subdivided into 2 pairs with one pair assigned for the thickness swelling (TS) and water absorption (WABS) and one for the moisture content (MC) and specific gravity (SG) tests. 


\section{Statistical Analysis}

A completely randomized design with four treatments (CR-4) was used to test the hypothesis of differences among wood fiber-cement product types for each test performed. Pairwise comparisons among means were performed using the Ryan Einot Gabriel-REGWQ multiple range test with a significance level of 0,05 .

\section{RESULTS AND DISCUSSION}

Table 3 shows the summary of results of the physical and mechanical properties tests of the WFC sheets.

Table 3. Results of mechanical and physical tests of WFC sheets*

\begin{tabular}{|c|c|c|c|c|c|c|c|c|c|}
\hline \multirow{2}{*}{$\begin{array}{c}\text { Sheet } \\
\text { Type }\end{array}$} & $\mathbf{R}^{* *}$ & $\mathbf{E}$ & $\mathbf{S}$ & $\mathbf{U}$ & $\mathbf{M}$ & $\mathbf{T S}$ & $\mathbf{W A B S}$ & $\mathbf{M C}$ & \multirow{2}{*}{ SG } \\
\cline { 2 - 9 } & $\mathbf{( M P a )}$ & $\mathbf{( G P a )}$ & $\mathbf{( M P a})$ & $\mathbf{( l b} \mathbf{f t} / \mathbf{f t})$ & $\mathbf{( l b} \mathbf{l} \mathbf{f t} / \mathbf{f t})$ & $\mathbf{( \% )}$ & $\mathbf{( \% )}$ & $\mathbf{( \% )}$ & \\
\hline \multirow{2}{*}{$\mathrm{A}^{* * *}$} & $18,6^{\mathrm{a}}$ & $6,99^{\mathrm{ab}}$ & $13,7^{\mathrm{a}}$ & $4,9^{\mathrm{a}}$ & $71,2^{\mathrm{a}}$ & $0,28^{\mathrm{a}}$ & $29,26^{\mathrm{a}}$ & $3,78^{\mathrm{a}}$ & $1,21^{\mathrm{b}}$ \\
& $(1,08)$ & $(0,60)$ & $(1,21)$ & $(0,55)$ & $(6,39)$ & $(0,19)$ & $(2,18)$ & $(0,13)$ & $(0,02)$ \\
\hline \multirow{2}{*}{$\mathrm{B}$} & $19,3^{\mathrm{a}}$ & $7,60^{\mathrm{ab}}$ & $14,0^{\mathrm{a}}$ & $5,1^{\mathrm{a}}$ & $74,8^{\mathrm{a}}$ & $0,22^{\mathrm{a}}$ & $31,02^{\mathrm{a}}$ & $3,69^{\mathrm{a}}$ & $1,23^{\mathrm{b}}$ \\
& $(3,21)$ & $(1,05)$ & $(1,47)$ & $(1,16)$ & $(13,77)$ & $(0,17)$ & $(1,18)$ & $(0,10)$ & $(0,06)$ \\
\hline \multirow{2}{*}{$\mathrm{C}$} & $11,7^{\mathrm{c}}$ & $6,58^{\mathrm{b}}$ & $9,3^{\mathrm{b}}$ & $2,2^{\mathrm{b}}$ & $42,6^{\mathrm{b}}$ & $0,21^{\mathrm{a}}$ & $32,06^{\mathrm{a}}$ & $3,65^{\mathrm{a}}$ & $1,19^{\mathrm{b}}$ \\
& $(0,77)$ & $(1,01)$ & $(1,02)$ & $(0,35)$ & $(3,5)$ & $(0,26)$ & $(3,69)$ & $(0,09)$ & $(0,06)$ \\
\hline \multirow{2}{*}{$\mathrm{D}$} & $14,5^{\mathrm{b}}$ & $7,97^{\mathrm{a}}$ & $10,5^{\mathrm{b}}$ & $2,8^{\mathrm{b}}$ & $36,1^{\mathrm{b}}$ & $0,29^{\mathrm{a}}$ & $24,29^{\mathrm{b}}$ & $3,40^{\mathrm{b}}$ & $1,33^{\mathrm{a}}$ \\
& $(1,51)$ & $(1,19)$ & $(0,77)$ & $(0,15)$ & $(3,42)$ & $(0,14)$ & $(0,70)$ & $(0,16)$ & $(0,02)$ \\
\hline
\end{tabular}

Note: Means within a column followed by the same lowercase letter are not statistically significantly different at 0,05 level of significance using the REGWQ F test. Numbers in parentheses are standard deviation.

(*) Tested at normal condition $\left(77^{\circ} \mathrm{F}\right.$ and $\left.45 \% \mathrm{RH}\right)$

(*) Tests:

$\mathrm{R}=$ Modulus of Rupture

$\mathrm{E}=$ Modulus of Elasticity

$\mathrm{S}=$ Stress at Proportional Limit

$\mathrm{U}=$ Handleability Index

$\mathrm{M}=$ Breaking Moment

TS= Thickness Swelling

WABS $=$ Water Absorption

$\mathrm{MC}=$ Moisture Content

$\mathrm{SG}=$ Specific Gravity
${ }^{* * *}$ WFC Sheets Fiber Types:

A=Douglas fir fiber @ kappa number 25

B=Douglas fir fiber @ kappa number 35

$\mathrm{C}=\mathrm{OCC}$ fiber

$\mathrm{D}=$ Commercial sheets 


\section{Mechanical Testing}

Mechanical properties of modulus of rupture (R), modulus of elasticity (E), stress at proportional limit (S), handleability index (U), and breaking moment $(\mathrm{M})$ were investigated.

Regarding the Douglas fir fiber used at kappa numbers 25 (Sheet A) and 35 (Sheet B), the results indicated no statistically significant difference for either physical or mechanical properties between the two sheet types. Sheets manufactured with Douglas fir fiber (Types A and B) presented systematically higher mechanical properties compared with WFC products $\mathrm{C}$ and $\mathrm{D}$. The only exception was modulus of elasticity. No statistically significant difference was observed among sheets A and B and the commercial product (D) for this property. Regarding flexural strength at equilibrium condition the WFC products tested could be graded according to ASTM C-1186-08 (ASTM 2008). Sheets type A and $\mathrm{B}$ would fit in grade III, whereas sheets $\mathrm{C}$ and $\mathrm{D}$ would be classified as grade II. The proposed grading system goes from grade I to IV in ascending order of strength.

Some samples of the commercial product (Sheet D) presented delamination all the way lengthwise when tested for 3-point bending strength. The cleavage occurred probably in one layer jointing. Since this product is manufactured in a layering process, the point of junction between two adjacent layers can contribute to sample failure at an earlier stage. Failure occurs mainly if the layer junction is off the neutral axis of the sample, where the compression or tension is higher than the centerline. Although product $\mathrm{D}$ presented higher specific gravity than the other sheet types, this fact did not improve its mechanical properties overall when compared to other sheet types. The explanation for this is discussed in the scanning electron microscopy analysis section.

WFC sheets manufactured using recycled OCC fiber (Sheet C) as reinforcement showed some properties (stress at proportional limit, handleability index, breaking moment and thickness swelling) comparable to the commercial product (Sheet D). However, half of the sheets made with OCC fiber presented bubble-like defects after autoclaving and half were defect free. This kind of fiber, due to its higher lignin content, is not as compatible with cement as kraft fibers are (Products A, B, and D). The higher amount of lignin present in the OCC fiber is liberated when the sheet is exposed to the high alkaline nature of Portland cement and the harsh environment during autoclaving. The lignin released influences cement setting, retarding its cure. Even though statistically significant differences were not observed between defective and sound specimens, as observed by the low standard deviation values, OCC fiber should not be considered if WFC sheets are to be cured by the current autoclaving process. Air-curing is the most appropriate process when employing OCC fiber as raw material for WFC sheets as shown in a previous study conducted by Teixeira (2012).

Sheets manufactured using Douglas fir fiber (A and B) had a higher handleability index than the other sheet types. The handleability index indicates the ease with which a sheet can be handled without buckling or breaking. This is an important property of WFC sheets used for siding since these products are normally about 8-12 inches (203-305 $\mathrm{mm}$ ) wide by some 12 or more feet long. The higher the handleability index the higher the ease of handling the sheet. Sheets type C and D can be grouped together as far as handleability index goes since they presented comparable values. The same pattern was observed for the property of breaking moment. A higher breaking moment indicates a higher breaking resistance of the material. It is particularly important for WFC products intended for roofing tiles.

\section{Physical testing}

Physical properties studied in this experiment were water absorption (WABS), thickness swelling (TS), moisture content (MC), and specific gravity (SG). Results of thickness swelling displayed in Table 3 showed no statistically significant difference among the four WFC products tested. The low thickness swelling is a quality normally found in this kind of composite. The combination of the compacted matrix with the low porosity offered by WFC products, compared to other wood composites, contribute to its high dimensional stability. One factor observed is that although the commercial product (Sheet D) had a higher specific gravity than the others, it did not revert to lower thickness swelling as would be expected. The thickness swelling generally decreases as the specific gravity of the material increases other variables remaining constant. 
On the other hand, specific gravity seems to have had a positive effect on the water absorption for product $\mathrm{D}$. The commercial product presented the smallest water absorption among the products tested. This physical property generally follows the same trend of thickness swelling as related to the sample specific gravity. Porosity, thickness swelling, water absorption, and specific gravity are correlated and dependent on the ability of the fine fibers to pack more efficiently inside the matrix. This characteristic contributes to lowering water absorption of the material. The three experimental WFC products (A, B, and C) were manufactured under the same process and, therefore, exhibited no statistically significant difference in specific gravity.

Results of the physical testing indicated that the difference in the fiber kappa number, and consequently lignin content, did not have any impact on the properties of the WFC sheets made with Douglas fir fiber (Sheets A and B).

\section{Scanning Electron Microscopy Analysis}

A scanning electron microscopy (SEM) analysis was conducted in order to get insight on the microstructure of the failure mode of the fibers. The analysis was performed on the fractured surface of the samples submitted to bending strength test.

Figures 1-6 showed that both fiber fracture and pullout occurred for the samples tested. Fiber fracture predominated over pullout in the sheets C and D. Figure 1 shows a fractured group of fibers from sheet $\mathrm{C}$ in the lower magnification side. In the same figure, a close-up (higher magnification) shows how the fiber broke. Sheet type $\mathrm{C}$ is made of recycled OCC fiber that has short length and a high percentage of broken fibers to start with before making the sheets.

Figure 2 and Figure 3 display a broken fiber from the commercial product (Sheet D). The ribbonlike fiber has either cleavage (Figure 2) or broken ends (Figure 3) as seen on the magnified side of the figures. The higher fiber breakage of product $\mathrm{D}$ indicates a strong matrix-to-fiber bond. As the bond is stronger than the fiber, the latter breaks.

Figure 4 and Figure 5 show the surface of the samples that presented lengthwise delamination in the bending test. The surface was smooth and the SEM analysis revealed that such delamination took place in a junction between two layers of the sheet. The figures reveal only fibers aligned along the surface, but no fiber interlocking was evidenced. Another observation drawn from Figure 5 is that there is a gap $(g)$ between the fiber $(f)$ and the matrix $(m)$, which could have contributed to the sample rupture. Possible causes for the gap could be shrinking of the fiber during drying or lateral contraction of the fiber under tensile loading. Such a problem was not identified on the other three WFC products because they were not manufactured in a layering process.

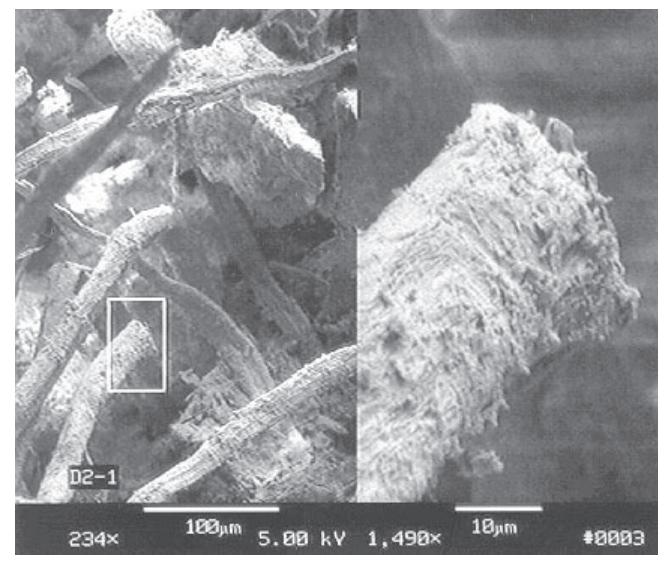

Figure 1. SEM analyses showing fractured OCC fibers from sheet type C.

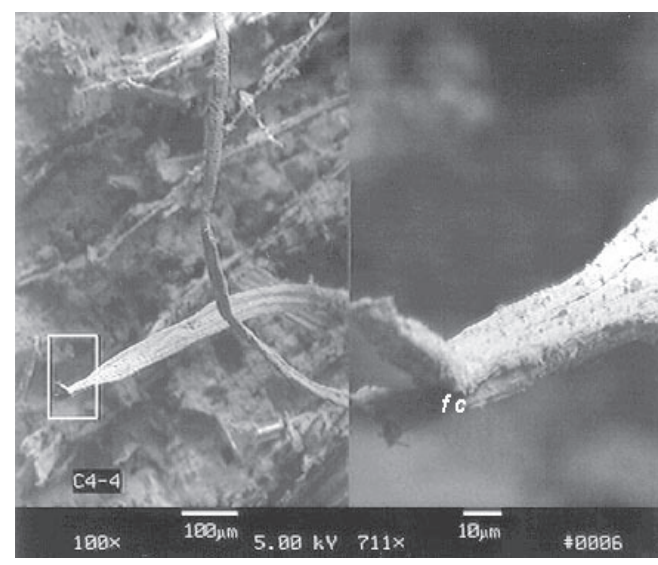

Figure 2. SEM analyses showing fractured fibers from sheet type D. Fiber cleavage (fc) is observed in the higher magnification. 


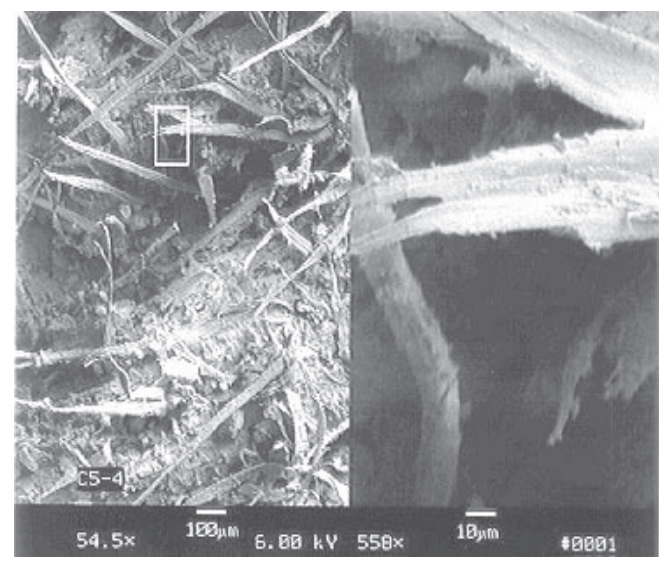

Figure 3. SEM analyses showing fractured fibers from sheet type D. Fiber with broken end is showed in the higher magnification.

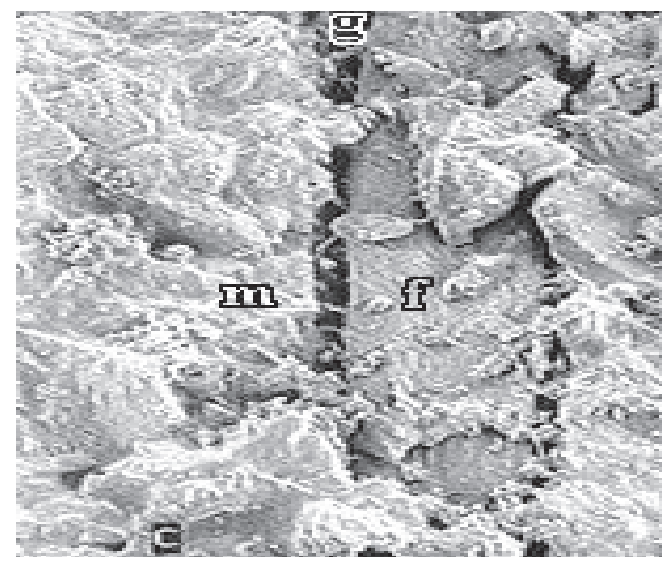

Figure 5. SEM analyses showing surface of sheet type $\mathrm{D}$ with delamination. The higher magnification shows gap $(\mathrm{g})$ between the fiber (f) and matrix (m).

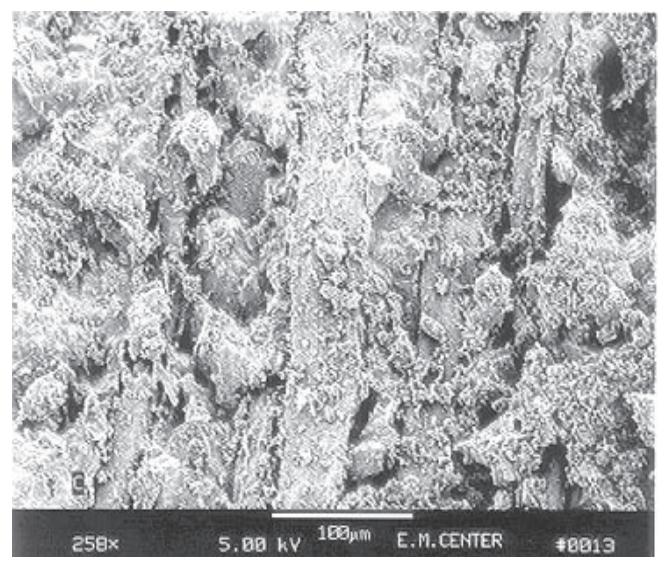

Figure 4. SEM analyses showing surface of sheet type $\mathrm{D}$ with delamination.

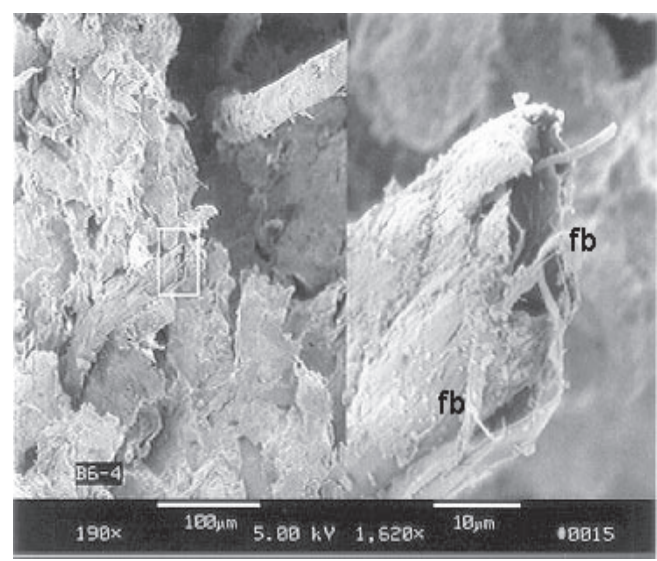

Figure 6. SEM analyses showing broken ends of Douglas fir fiber (Sheet B). Notice the fibrillation ( $\mathrm{fb}$ ) exposed by refining.

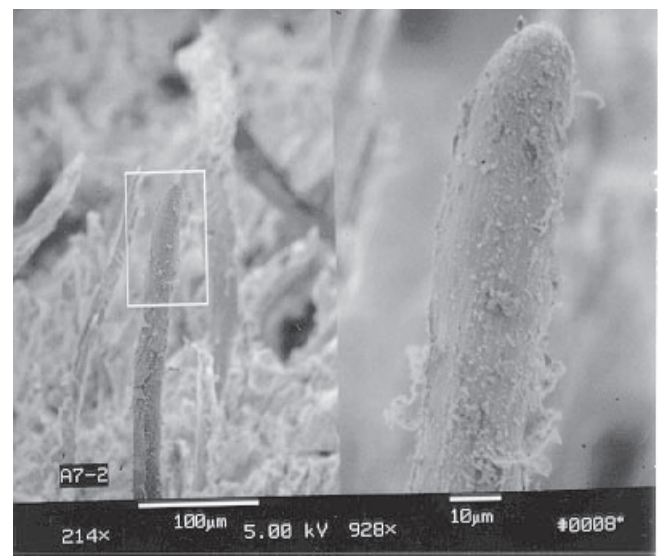

Figure 7. SEM analyses showing intact Douglas fir fiber pulled out from WFC matrix. 
To better explain what most likely occurred in the delamination of sample from sheet $\mathrm{D}$, the drawing in the figure below is appropriate (Figure 8). In the junction between two laminates of the multi-layer sheet in part (a) there is not as much fiber (2) interlocking as there is in the monolithic sheet (b). Instead, cement hydration causes mechanical interlocking or anchorage points (1) between layers in the WFC sheet due to crystal growth during the process. In the region between two layers, these linkages are brittle and interlocking fibers are not present to stop microcracks from becoming major cracks; consequently, failure occurs faster. In a monolithic sheet (part $b$ ) the presence of interlocking fibers (2) throughout the sample helps to stop the microcracks; to cause failure, matrix as well as fiber strength would need to be overcome. In the layered sheet, fiber interlocking is present inside each layer but is minimal in the layer-to layer junction.

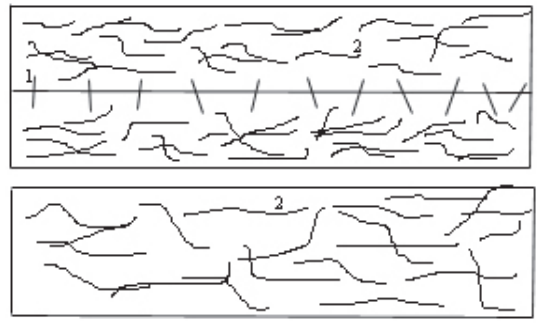

a)

b)

Figure 8. Schematic representation of the forming method of the multi-layer $(a)$ versus single layer (b) process in WFC sheets.

WFC materials have a tensile stress/strain curve and there is sufficient fiber to support the extra load when the matrix cracks, so the product can resist failing further. When the sample's matrix starts to crack, it continues at constant stress but increasing strain. The multiple cracks continue until the distance between cracks is too small to allow transfer of sufficient load from fiber to matrix to crack it further. Thereafter, further increase in load is taken by fibers alone and, hence, the strength of the composite depends solely on the fiber strength.

Figure 6 and Figure 7 show the SEM analysis for WFC samples with Douglas fir fiber. Although fiber breakage and pullout occurred in these WFC products, the former is outnumbered by the latter. The pullout shows that the fiber at that position is stronger than the matrix bond. It can contribute to a longer resistance of the sheet to ultimate failure. In addition, the fact that sheets A and B were formed in a monolithic process can be used as evidence for the higher strength of such products compared to others. No delamination was observed for them after testing.

Figure 6 reveals the broken end of Douglas fir fibers. Notice the fibrillation $(f b)$ sticking out of the fiber. These fibrils are exposed when the fiber is refined. The purpose of refining is achieved when the fiber retains more solids. Intact fibers were also pulled out of the matrix as presented in Figure 7.

\section{CONCLUSIONS}

An experimental study was conducted to determine the physical and mechanical properties of autoclaved WFC sheets. Virgin and recycled cellulose fibers were used to manufacture experimental sheets in a slurry-dewatered technique. The sheets were tested and results compared with an available commercial product. The results indicated the following:

Douglas fir is a good alternative raw material for reinforcing WFC flat sheets at the fiber standpoint. Results in the present study showed superior performance for all mechanical properties, but modulus of elasticity. No statistically significant difference was detected among Douglas fir sheets and a commercial product. The difference in kappa number of the Douglas fir fibers used did not have any 
effect on the properties of the sheets tested. There was no statistically significant difference whatsoever for any of the properties studied. Taking in account the autoclave regime used, it was evident that OCC fiber is not a feasible raw material for reinforcing autoclaved WFC sheets. Concerning physical properties, the experimental sheets with Douglas fir fibers are comparable to the commercial product. The only advantage of the latter refers to its ability to absorb less water (due to higher density). The SEM analyses showed that WFC sheets presented a dual mechanism of fiber pull out and breakage at rupture. Fiber breakage predominated in the commercial product whereas pull out was slightly higher in the sheets with Douglas fir fibers.

Although this experimental research provided a number of satisfactory results, it is suggested that autoclaving of OCC fiber Sheets should be further explored employing different pressure and temperature regimes in an attempt to solve curing problems encountered with autoclave. Furthermore, it is recommended that a freeze/thaw test be included in future experiments. This test detects possible cracking, delaminating, and other defects in the WFC sheets.

\section{REFERENCES}

Abdel-Kader, A.H.; Darweesh, H.H. 2010. Setting and hardening of agro/cement composites. BioResources 5(1): 43-54.

American Forest \& Paper Association. AF\&PA. 2018a. Recovery \& use of old corrugated containers (OCC). [on line] Available at <http://www.paperrecycles.org/>. [Access: July 17, 2018].

American Forest \& Paper Association. AF\&PA. 2018b. Recovery of old newspapers/mechanical papers. [on line]. Available at <http://www.paperrecycles.org/> [Accessed: July 17, 2018].

Alda, J.A.G.O.; Torrea, J.A. 2006. Applications of recycled paper mills effluents to wood substitute products (RESPRO): executive Summary. Oppidium, Universidad SEK, no. 2, pp. 381-398.

Almeida, R. R.; Del Menezzi, C.H.S.; Teixeira, D.E. 2002. Utilization of the coconut shell of babaçu (Orbignya sp.) to produce cement-bonded particleboard. Bioresource Technology 85(2): 159163.

Araújo, P.C.; Arruda, L.M.; Del Menezzi, C.H.S.; Teixeira, D.E.; Souza, M.R. 2011. Lignocellulosic composites from Brazilian giant bamboo (Guadua magna). Part 2: properties of cement and gypsum bonded particleboards. Maderas-Cienc Tecnol 13(3): 297-306.

Ardanuy, M.; Claramunt, J.; Toledo Filho, R.D. 2015. Cellulosic fiber reinforced cement-based composites: a review of recent research. Construction and Building Materials 79: 115-128.

American Society for Testing and Materials. ASTM. 2008. Standard test methods for sampling and testing non-asbestos fiber-cement flat sheet, roofing and siding shingles, and clapboards. ASTM C-1185-08. Annual Book of the ASTM Standards, Volume 04.05. American Society for Testing and Materials: Philadelphia, PA.

American Society for Testing and Materials. ASTM. 2008. Standard specification for flat nonasbestos fiber-cement sheets. ASTM C-1186-91. Annual Book of the ASTM Standards, Volume 04.05. American Society for Testing and Materials: Philadelphia, PA.

American Society for Testing and Materials. ASTM. 2006. Standard methods of evaluating the properties of wood-base fiber and particle panel materials. ASTM D-1037-06. Annual Book of the ASTM Standards, Volume 04.10. American Society for Testing and Materials: Philadelphia, PA.

Cheng, X.W.; Khorami, Morteza.; Shi, Y.; Liu, K.Q.; Guo, X.Y.; Austin, S.; Saidani, M. 2018. A new approach to improve mechanical properties and durability of low-density oil well cement 
composite reinforced by cellulose fibres in microstructural scale. Construction and Building Materials 177: 499-510.

Farrapo, Camila L.; Fonseca, Camila S.; Pereira, Tamires G.T.; Tonoli, Gustavo H.D.; Savastano Junior, Holmer.; Mendes, Rafael F. 2017. Cellulose associated with pet bottle waste in cement based composites. Materials Research 20(5): 1380-1387.

Ferraz, J.M.; Del Menezzi, C.H.S.; Teixeira, D.E.; Martins, S.A. 2011. Effects of treatment of coir fiber and cement/fiber ratio on properties of cement-bonded composites. BioResources 6(3):34813492.

Fonseca, Camila S.; Silva, Thaís F. da.; Silva, Matheus F.; Oliveira, Isabela R. de C.; Mendes, Rafael F.; Hein, Paulo R.G.; Mendes, Lourival M.; Tonoli. Gustavo H.D. 2016. Micro/nanofibrilas celulósicas de eucalyptus em fibrocimentos extrudados. Cerne 22(1):59-68.

Frazão, Cristina.; Barros, Joaquim.; Filho, Romildo Toledo.; Ferreira, Saulo.; Gonçalves, Delfina. 2018. Development of sandwich panels combining sisal fiber-cement composites and fiberreinforced lightweight Concrete. Cement and Concrete Composites V 86: 206-22.

Khoramia, Morteza.; Ganjiana, Eshmaeil.; Srivastav, Anupam. 2016. Feasibility study on production of fiber cement board using waste kraft pulp in corporation with polypropylene and acrylic fibers. Materials Today: Proceedings 3(2016) 376-380.

Marques, Maria L.; Luzardo, Francisco H.M.; Velasco, Fermin G.; González, Luis Nieto.; Silva, Everton J. da.; Lima, de Wellington G. 2016. Compatibility of vegetable fibers with Portland cement and its relationship with the physical properties. Revista Brasileira de Engenharia Agrícola e Ambiental 20(5): 466-472.

Moslemi, A.A. 2008. Technology and market considerations for fiber cement composites. In: Proceedings of the 11th International Inorganic Bonded Fiber Composites Conference (IIBCC'08), Madrid, Spain, November.

Sahin, H.T.; Yilmaz, Mustafa.; Demiratli, Seda. 2017. Treatments of recycled pulps from old corrugated containers. Part I. The effects of boron compounds on optical and physical properties. Asian Journal of Chemical Sciences 3(3):1-8.

Santos, S.F.; Tonoli, G.H.D.; Mejia, J.E.B.; Fiorelli, J.; Savastano Jr, H. 2015. Non-conventional cement-based composites reinforced with vegetable fibers: A review of strategies to improve durability. Materiales de Construcción, 65(317): 41.

Soydan, Ali M.; Sari, Abdul K.; Duymaz, Burcu.; Akdeniz, Recep.; Tunaboylu, Bahadır. 2018. Air-cured fiber-cement composite mixtures with different types of cellulose fibers. Advances in Materials Science and Engineering 2018 Article ID 3841514: 9p

Technical Association of the Pulp and Paper Industry. TAPPI. 1994. Kappa Number of Pulp. TAPPI T 236 cm-85, TAPPI Press: Atlanta, Ga, USA.

Teixeira, D.E. 2012. Recycled old corrugated container fibers for wood-fiber cement sheets. ISRN Forestry 2012 Article ID 923413: 8p

The Freedonia Group. 2018. World Fiber Cement. Industry Study with Forecasts for 2019 \& 2024. Study \#3273. Available at < https://www.freedoniagroup.com>. [Access: July 17, 2018].

Wei, J.; Ma, Siwei.; Thomas, D'Shawn G. 2016. Correlation between hydration of cement and durability of natural fiber-reinforced cement composites. Corrosion Science 106, 106: 1-15. 